\title{
60
}

\section{Global concurrent engineering approach for production systems}

\author{
D.BREUIL, M ALDANONDO \\ Ecole Nationale d'Ingénieurs de Tarbes - Laboratoire Génie de Production \\ Avenue d'Azereix - BP 1629. 65016 Tarbes FRANCE \\ Tel : (33) 62442716 - Fax : (33) 62442708
}

\begin{abstract}
Basic studies are the first phase of an engineering project. They aim to determine solutions in order to improve performances of production units, to evaluate their feasibility, their profitability, and to establish the planning of their installation.

They concern the three domains of the production systems, the product design, the process definition and the management. Such studies may be decomposed in six functional steps, dealing with the components of these domains

This paper focuses on the physical organisation design (of production and flows activities) and the management design (decision system), and their relations.

The goal of this communication is to present an approach for Global Concurrent Engineering which improve the co-ordination between those two domains. The main points of the proposed approach deal mainly with :

- the links and influences between decision system, physical organisation and resources design (what, when, how they must be taken in account during the whole design process)

- the identification of constraints for these design steps, nature of which may come from technical aspects, implementation environment, or financial objectives

- the evaluation of the consequences of design alternatives
\end{abstract}




\section{1- INTRODUCTION}

Production systems engineering aims to design or renew all the components which participate to the production. These components include mainly:

- the physical elements, ie all the resources like equipments, workers,..required for manufacturing, maintaining, preparing, distributing..

- the management which can be split in decision and information systems with their own organisation, mechanisms and resources

- the interfaces between the production system and its environment which can be internal or external to the company

Such projects are normally decomposed in several phases, from the very first global studies to the launching of exploitation This decomposition is made according to a hierarchical approach which allows at each level, to evaluate the feasibility and the profitability of the proposed solutions. Criteria for this decomposition may be different from one project to another; they may consider the production system according to different points of view, either the company domains or departments (production, maintenanc, information,...) or the functions to be modernised (civil engineering, automatisms, assembly, logistics,..) or else the manufacturing organisation (workshop 1 , workshop 2, warehouse,...).

Basic Studies are the first phase of an engineering project. Their aim is to determine global solutions in order to improve perfomances of production units, to evaluate their feasibility, their profitability, and to establish the planning of their installation.

During these studies, designers must choose between various alternatives upon the different components of the production system. However for many different reasons (like time and costs allocated to these studies, process definition,...), their decisions are based on global views, even though they must get clear enough precision on the future in order to find a realistic cost balance.

Many research works propose to help developers during design phases. Quite often they are oriented towards detailed studies activities and they address only few aspects of them. However, some of them may be used at global level as we will see later..

Two generic ways have been the subjects of several works which are not global studies beginning oriented, but their principles or concepts may be adapted for this purpose : re-engineering and concurrent engineering.

a) re-engineering concerns the fundamental transformation of the processes inside the organisation or the structure of a company, from the top management to the bottom; it is aimed to prepare the organisation to permanent evolution.

Several methods have been proposed in that domain which are oriented towards the management of the company changes from human resources or company culture point of view supported by the different possibilities offered by information technology. 
However, re-engineering approaches do not take into account the production (or manufacturing) processes.

b) The definition for Concurrent Engineering stated by US Institute for Defence Analysis (report R-338, 1988) considers Concurrent Engineering as "a systematic approach to the integrated, concurrent design of products and their related processes including manufacturing and support. This approach is intended to cause the developers, from the outset, to consider all elements of the product life-cycle from conception through disposal, including quality, cost, schedule and user requirements".

The parallelisation of the design processes (proposed in this definition) is quite necessary for the management of Basic Studies; however, approaches presented in the majority of research works are too much detailed for their global level.

\section{2- BASIC STUDIES}

Basic Studies concern all the domains of the production systems, the product design, the process organisation, the management and the information systems. Such studies may be decomposed in functional steps, dealing with the components of these domains. During such studies very strong interactions occur between the steps.

Results coming out of Basic Studies include the global description of the solution which concern mainly:

- the type and characteristics of all the resources that will be used (from buildings to containers for products transportation inside workshops),

- the different flow operating rules,

- the layout of resources and various charts adapted to different points of view (ex civil engineering, circulation of people, or energies,...)

- the structure of decision system,

- the organisation and resources allocated to information system

The following simplified diagram (figure 1) shows the main relations between the different steps of Basic Studies.

As this diagram shows, there are loops between the steps, especially at the interfaces between the domains. If design process is considered as a sequence, each step may lead to modify the results of one or more previous ones because, from its point of view, some impossibility to meet required performances occurred.

This may come for instance from technical difficulties in equipments design which implies to modify the production activities or from the optimisation of management which requires to re-organise workshops.

More over, design at each step must take into account constraints coming from the general environment (market trends, expected output flows,...), from the company strategies on its own domain and from forecasted exploitation of the future production system.

The main steps are concerned with :

a) The design of products concerns the general definition of the products and the associated production activities. 
b) The design of the physical organisation concerns :

- the definition and the dimensioning of equipments as well as their layout

- the definition of all the facilities for the support of production activities, from the buildings to the energies,

- the flow regulation rules adapted to the required performances for the production systems

- the required resources for all the internal logistics

c) The design of decision and management system deals with the organisation of :

- the definition and organisation of decision functions and decision centres in each function,

- the management organisation of human resources and the definition of required competencies.

d) The design of information system considers the organisation and the resources which may be implemented to support all the other components of the production system. This starts with the definition of data organisation and processing and leads to the definition of required types of equipments, packages, networks,...

e) The last functional step concerns the planning of the implementation of the proposed solutions and the estimation of the costs and profitability of the total project.

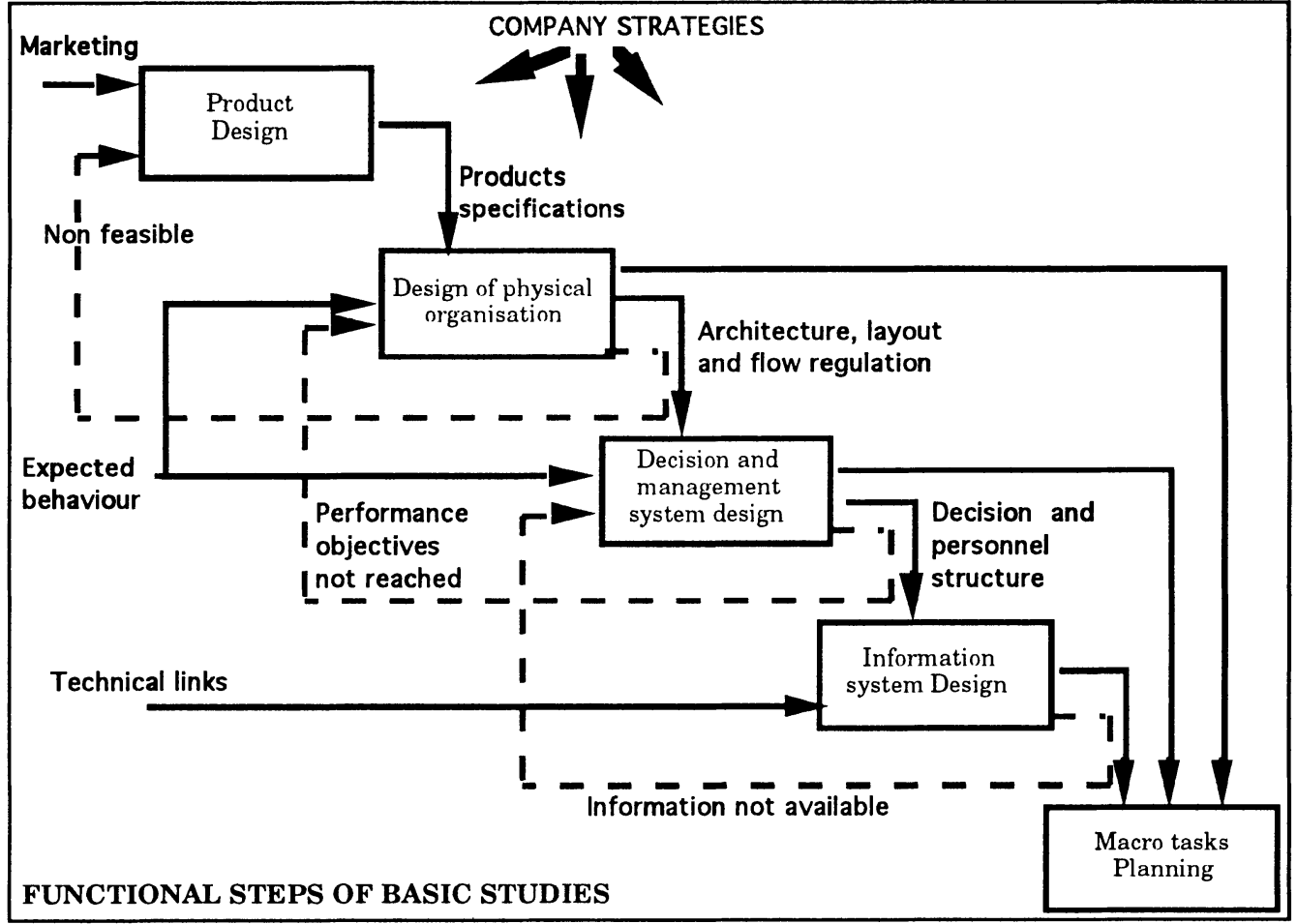

Figure 1

For all those steps, different competencies among the designers are involved in order to handle efficiently all the point of views. One way to bring together all correct 
informations consist in grouping designers in teams to obtain proper co-operation level; but meetings cannot stand full time; so the need of concurrency in design activities implies the distribution of coherent and right informations for all partners in a project. Since influences from one point of view may be of interest for all others and reciprocally, the network of informations exchange is quite large. Further more, data used at this design level are global and aggregated data, representing several aspects of the future production system.

\section{3- DESIGN RELATIONS BETWEEN PHYSICAL AND MANAGEMENT ORGANISATION}

\section{1- organisation of physical system}

The design process may be decomposed in 6 main activities (figure 2):

- the first one deals with the flow analysis; this is a critical point since these flows are not always clearly identified at the Basic Study level for different reasons which are related to the difficulty to get representative flow (and products) data inside the company and the fuzziness of company objectives regarding the expected or forecasted product flows out of the company.

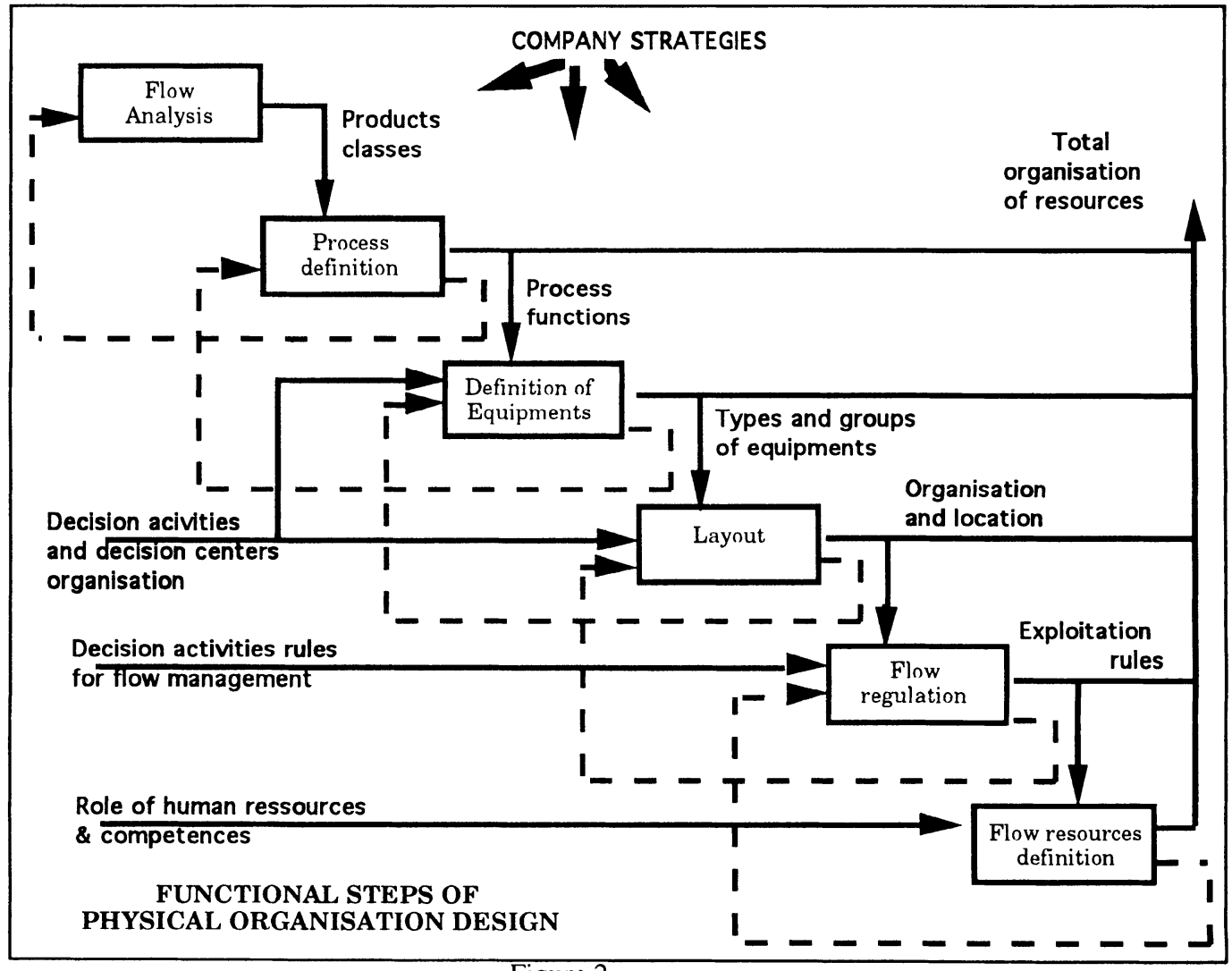

Figure 2 
- then the process definition will point out the functions required for manufacturing the products

- the definition of equipment will lead to the definition of the nature and global performances of equipments that will be required to perform the production activities.

- layout activity aims to organise and structure workshops and inside them major groups of equipments according to the different possible choices offered by the previous activity

- flow regulation activity is concerned with the architecture of the flow management

- flow resources definition activity is in charge of the determination of the resources associated to the product flow and storage.

\subsection{Management organisation}

These activities aim to determine the decision structure according to the required performances for the production system and the organisation of human resources associated to this structure.

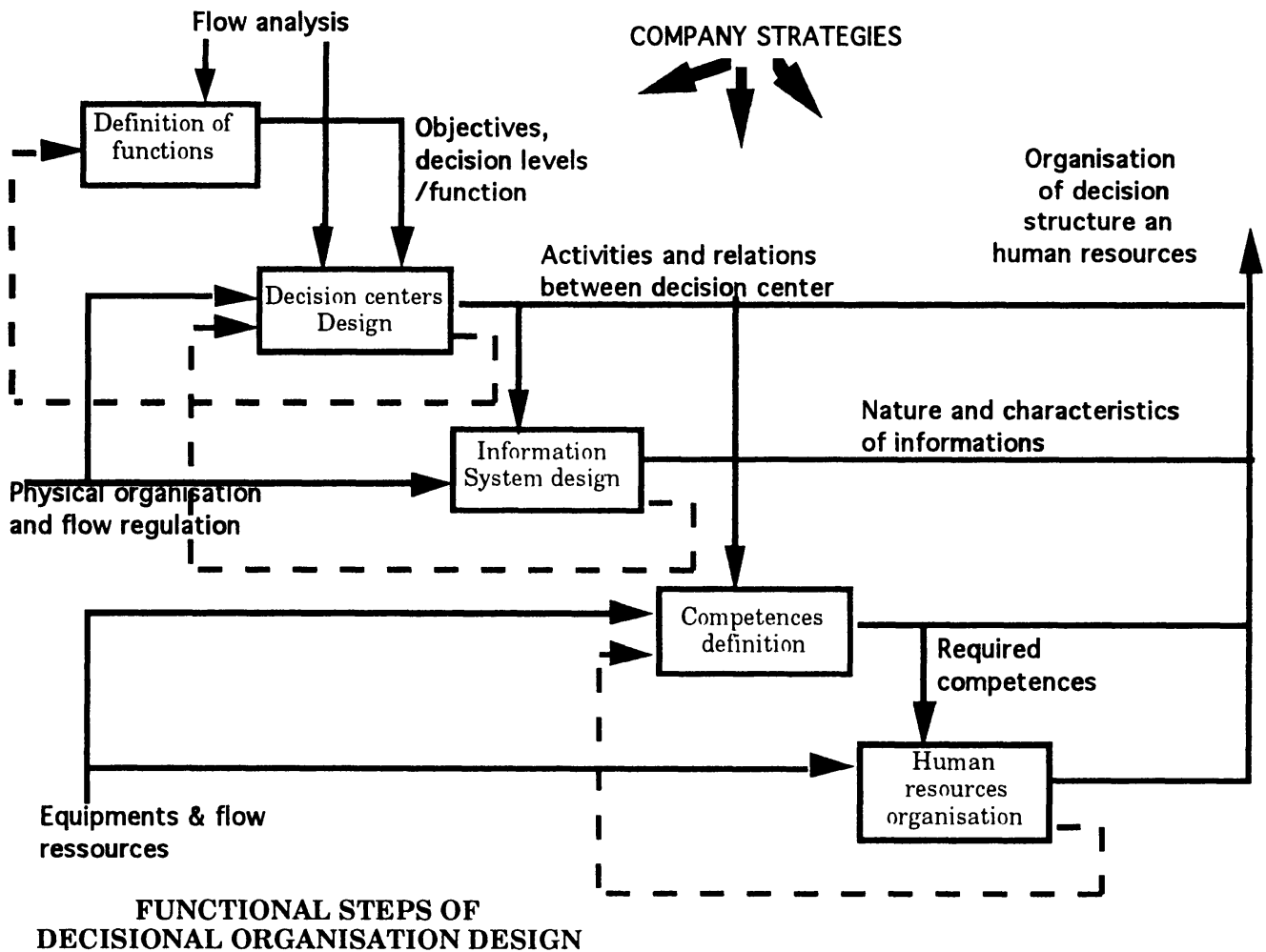

Figure 3

The decision structure covers all management functions of the considered production system (that may include sometimes logistics functions, suppliers relations,..) from the 
top level of production management to the decision taken in real time inside workshops. Five main activities may be identified at the level of Basic Studies:

- the definition of management functions and of the global architecture of decision centres

- the definition of the activities inside each decision centres and the informations they need

- the design of the architecture of the information system

- the definition of the required competencies for managing each decision centres; this is particularly important when the improvements of decision structure introduce new concepts, new decision rules or new relations between decision makers.

- the organisation of the human resources for identifying groups of personnel, relations between groups and the structure of this organisation.

\subsection{Relations between the design processes}

On these diagrams, the main links between these processes are shown and they pointed out the strong relations that exist between those organisations.

In fact, quite often, the stating of a physical organisation determines flow regulation decisions; but such a choice depends on management principles of the flows (decision aspect) which depend themselves on the nature of the process which have been designed and such reasoning could go on again,...

If design processes are conducted separately, there will be of course many chances to spend a long time for adapting each one at the end when designers come together.

On the other hand, if the different steps are simply integrated, sequenced just one after the other or if designers met at some times, there will be also a lot of time lost in discussions or in re design

\section{4- STRUCTURE OF THE PROPOSED APPROACH}

The optimisation of the objectives of the designed production system depends mainly on the coherence of all the different flows which will exist in this system and above all the physical and decisional ones.

So, in order to minimise the backward loops we mentioned above or the loss of time, conflicts, etc,... it is necessary to :

- design simultaneously those flows

- to co-ordinate the other design functions from the design decisions taken upon the flows

Then the functional steps will be linked as it is shown in the figure 4. In this diagram, the activities dedicated to the specific design of process, equipments or management remain almost the same as previously. 


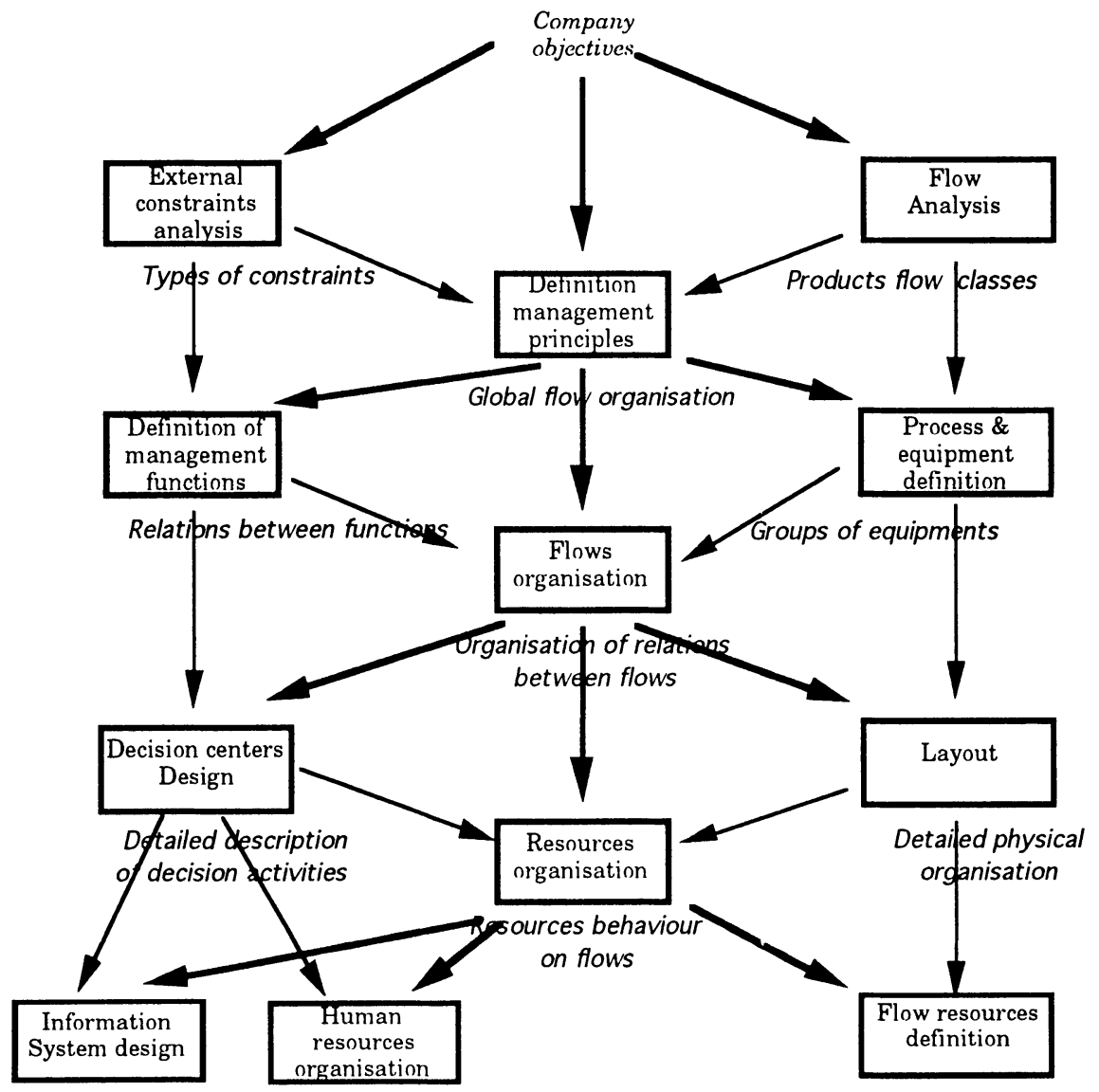

Figure 4

However, co-ordination design activities are the skeleton of all the design processes. The main co-ordination activities are:

- definition of flows management principles: this activity aims to define and adapt the general management principles to each class of product flows, to determine the types of management rules (technical or production management aspects) which will be applied to the products and decision flows according to the performance objectives and responses to external constraints. This will allow us to determine on one hand the necessary management functions and on the other hand the organisation of process functions.

- organisation of flows: this activity is concerned with the design of the architecture of flows. Once management functions and groups of equipment have been defined, it is necessary to examine their internal and external cross links and especially the interfacing points between the different flows. This will lead to the determination of the co-ordination between the different functions regarding the flows and to verify the coherence of the rules applied to these flows. 
- resource organization: this last important co-ordination activity first defines the relations between the resources associated with the different flows and their nature according to the performances they must reach. The objective is to establish the activity frame of these resources inside the production system and their possible influences on the different flows.

\section{5- CONCLUSIONS}

This approach for Basic Studies may be extended to the whole phases of an engineering project. Then we get a structured hierarchical approach over these phases; the criteria used for the structuration of the hierarchy is the degree of detail of the data used during these phases.

This methodology has been used for several companies (11 full approach, 4 partially, some more are under changes) in different market domains (food industry, wood industry, mechanical or chemical). The only common point between them was the size, no none was greater than 600 people and was challenged on costs and response time to customers. The small size simplified the relations between the global co-ordination process and others.

The results were the creation of small independent entities (20 to 50 people) or production units (sometimes subsidiaries) in which people were quite involved in the success of their activities. Most of them have their own independent management structure which includes commercial or purchasing functions even though they are coordinated by company management. In all cases the weight and complexity of centralised management was avoided (sometimes with difficulty) in order to let as large as possible autonomy to the units.

In these companies, objectives towards environment were reached (response time, costs, production volume increase...) and up to now they are still alive while some of their challengers disappeared in the mean time.

\section{REFERENCES}

AHMED (1994), M. S. AHMED, J. A. G. KNIGHT, H. S. ABDALLA, Global Concurrent Engineering, Intelligent Manufacturing Systems, IMS'94 (IFAC) Vienne, 1994.

ARVINDE (1994), B. ARVKNDH, S. A. IRANI, Cell formation: the need for an integrated solution of the subproblems. International Journal of Production Research, V 32, No 7, 1994.

BREUIL (1984), D. BREUIL, Outils de conception et ed decision dans les organisations ee gestion de production, These d'etat, Bordeaux, 1984.

BREUIL (1984), D. BREUIL, Schemas Directeur: episodes 1 et 2 Logistique et Management, V 1, No 1, 1993, V 2, No 1, 1994.

BURBIDGE (1989), J. L. BURBIDGE, Production Flow Analysis for Planning Group Technology, Oxford University Press, Oxford, 1989. 
BURBIDGE (1992), J.L. BURBIDGE, Changes to group technology: process organisation is obsolete, International Journal of Production Research, V 30, $\mathrm{n}^{\circ} 5$, 1992

BURBIDGE (1993), J.L. BURBIDGE, Group technology, where do we go from here?, Advances in Production Management Systems (APMS 93), Athens, Greece, September 1993

DAS (1993), S. K. DAS, A facility layout method for flexible manufacturing systems, International Journal of Production Research, V 31, n² 2, 1993

ESPRIT 7752 (1994), Architecture for Global Concurrent Engineering System, Deliverable 3.2

FERRAND (1994), D. FERRAND, G. PAQUET, Apprentissage organisationnel et Reengineering, Logistique et management, Vol 1, n², 1994

GALLOIS (1989), P-M. GALLOIS, Typologie des entreprises industrielles, Revue française de Gestion Industrielle, V 8, n 1,1989

GUHA (1993) S. GUHA, W. J. KETTINGER, J.T. TENG, Business Process Re-engineering: Building a comprehensive Methodology, Information Systems management, 1993

HALL (1993), G.HALL, J. ROSENTHAL, J. WADE, How to make re-engineering really work, Harvard Business Review, 71,6, 1993

M. HAMMER (1990), Re-engineering work: Don't automate, Obliterate, Harvard Business Review, 68,4 1990)

M. HAMMER, J.CHAMPY (1993), Le Reengineering, DUNOD, 1993

Mac LEAN, 1993, Computer-Aided Manufacturing System Engineering, Advances in Production Management Systems (APMS 93), Athens, Greece, September 1993

\section{BIOGRAPHY}

Dominique BREUIL (age 44) is Associated Professor at the Ecole nationale d'Ingénieurs de Tarbes since october 1993. Previously he worked as manager of Organisation Department in several engineering companies where he was in charge of the industrial organisation of the production systems designed by engineers of these companies.

Micehl ALDANONDO (age 34) is Maitre de Conférences at the Ecole nationale d'Ingénieurs de Tarbes 